\title{
Organ Damage in HIV-Positive Patients with High Blood Pressure
}

\author{
Maggi $\mathbf{P}^{1}$, De Socio $\mathrm{GVL}^{2}$, Volpe $\mathrm{A}^{1^{*}}$, Lenoci $\mathrm{F}^{1}$, Altizio $\mathbf{S}^{1}$, Leone AS ${ }^{1}$, Bellacosa $\mathbf{C}^{1}$, Angarano $\mathbf{G}^{1}$ and Antonelli $\mathbf{G}^{3}$
}

${ }^{1}$ Clinic Infectious Diseases, University of Bari, Italy

${ }^{2}$ Department of Infectious Diseases, Santa Maria Hospital, Perugia, Italy

${ }^{3}$ Department of Cardiology, Policlinico, Bari, Italy

\begin{abstract}
Our objective has been the investigation of possible cardiovascular or renal organ damage in HIV patients with confirmed high blood pressure by means of instrumental cardiovascular investigation and renal function evaluation. A total of 265 consecutive patients accessing our outpatient facility were enrolled in the study. Patients with confirmed pathological pressure values or high normal values were submitted to clinical and instrumental monitoring by 24-hour ambulatory blood pressure monitoring (ABPM), to derivation of 12-lead ECG registration, to echocardiography and to epi-aortic vessel echo-color-Doppler. The ECG and echocardiographic data were compared to a control group of 40 hypertensive HIV-negative subjects. Renal damage was evaluated by means of the microalbuminuria/creatininuria ratio on a spot urine sample, plus 24-hour albuminuria and proteinuria measurements. $61(23.0 \%)$ of the subjects examined were hypertensive: $24(39.3 \%)$ had a previous hypertensive diagnosis but had never been treated for this condition, and $37(60.7 \%)$ had a new diagnosis; In 100\% of cases, 24-hour ABPM confirmed the hypertension and $27.8 \%$ of the patients resulted non-dippers. The ECG showed left ventricle overload, V4-V6 strain, or left ventricular hypertrophy in $64.3 \%$ of cases compared to $35.7 \%$ in the control group. Echocardiography demonstrated increasing in left ventricle parietal thickness with concentric remodeling and hypertrophy in $85.2 \%$ of patients. HIV-positive patients showed a statistically significant tendency to concentric remodeling and concentric hypertrophy, even in presence of mild hypertension. Echocolor-Doppler examination detected intima-media thickness $>$ and/or carotid plaques in $72.1 \%$ of patients. Renal function seems spared in these subjects. Our data highlights the importance of investigating arterial hypertension among our patients as it is a frequently undiagnosed condition, and illustrates the utility of 24$\mathrm{hr}$ ABPM to confirm hypertension and to identify the non-dipper subject. Moreover, the ECG, echocardiography and echocolor-Doppler examinations evidenced a premature tendency to organ damage in these patients that showed altered cardiac remodeling compared to those without HIV. This stresses the need for an early diagnosis, including a complete instrumental evaluation to properly identify organ damage even at a subclinical level.
\end{abstract}

Keywords: Antiretroviral therapy; High blood pressure; Cardiovascular damage; Renal organ damage

\section{Background}

The introduction of highly active antiretroviral therapy (HAART) has resulted in a completely new approach to HIV-infection and has determined a lower association of morbidity and mortality, thus initiating a profound transformation of the disease which is progressively becoming a chronic condition. Nevertheless, the longterm toxicity provoked by HAART might present an obstacle to the hope of a life expectancy similar to that of the general population.

In particular, a disputed problem is that of high blood pressure in HIV-infected patients and its consequences in terms of organ damage. In fact, hypertension is a common condition in HIV-infected people, although the real prevalence is still unclear, ranging from 13 to $34 \%$ [1-3].

Hypertension is treatable disease, although, if neglected, it is considered a established risk factor for cardiovascular and kidney diseases. Nevertheless, few studies have reported the prevalence of important abnormalities in cardiac structure and function, blood vessels and kidneys among HIV-positive persons. 12-lead ECG registration, 24-hour ambulatory blood pressure monitoring (ABPM), echocardiography, epi-aortic vessel echo-color-Doppler, microalbuminuria/creatininuria ratio on a spot urine sample, plus 24-hour albuminuria and proteinuria measurements together with glomerular filtration rate (GFR) assessment, are simple, repeatable, inexpensive and well validated tools for the diagnosis of premature cardiovascular and kidney changes due to hypertension.

The objective of this study was to investigate possible cardiovascular or renal organ damage in HIV patients with confirmed high blood pressure by means of instrumental cardiovascular and renal function evaluation.

\section{Patients and Methods}

A total of 265 consecutive patients accessing our outpatient facility from September 2010 to September 2011 were enrolled in the study. Patients in treatment with antihypertensive agents and patients with acute pathologies were excluded.

Data collection (except imaging) occurred at the clinic site and coincided with subjects' schedule of routine blood collection. Imaging studies coincided with schedule of routine physical examination, generally no more than a fortnight later.

The blood pressure of each patient was measured after at least 5-10 minutes of rest, and each final value was based on the mean of three different measurements. The degree of hypertension was classified according to the European Society of Hypertension and European Society of Cardiology guidelines for the management of arterial hypertension [4]. Patients showing pathological pressure values with

*Corresponding author: Volpe Anna, Clinic Infectious Diseases University of Bari, Italy, Tel: +390805592185; Fax: +390805478333; E-mail: anna.volpe@uniba.it

Received July 27, 2013; Accepted September 28, 2013; Published October 06 , 2013

Citation: Maggi P, De Socio GVL, Volpe A, Lenoci F, Altizio S, et al. (2013) Organ Damage in HIV-Positive Patients with High Blood Pressure. J AIDS Clin Res 4: 248. doi: 10.4172/2155-6113.1000248

Copyright: @ 2013 Maggi P, et al. This is an open-access article distributed under the terms of the Creative Commons Attribution License, which permits unrestricted use, distribution, and reproduction in any medium, provided the original author and source are credited. 
alterations of either systolic or diastolic pressure $>140 / 90 \mathrm{mmHg}$ for hypertension or $>130 / 85 \mathrm{mmHg}$ for High Normal blood pressure confirmed in two different sessions within 6 months were submitted to clinical and instrumental monitoring by ABPM. Measurements were performed on a weekday with a validated oscillometric automatic device (SpaceLabs 90207, SpaceLabs, Redmond Wash.) which recorded $\mathrm{BP}$ and heart rate at 20-minute intervals during the day (07:00-22:00) and 30-minute intervals during the night (22:00-07:00). Cuff size was selected according to measured arm circumference and the nondominant arm was used. Patients were instructed to keep their arm still during BP measurements to ensure good-quality recordings. Hypertension diagnosis was confirmed if day-time readings were $\geq 135 / 85 \mathrm{mmHg}$ [4].

A nocturnal non-dipping blood pressure profile was defined as 10\% or lesser magnitude reduction in average systolic and/or diastolic blood pressure at night time compared to daytime systolic blood pressure average values. The remainder defined as dipping blood pressure $[5,6]$.

Patients were then submitted to derivation of 12-lead ECG registration, to echocardiography and to epi-aortic vessel echo-colorDoppler.

Left ventricular hypertrophy on ECG was defined as RaVl + SV3 $>24 \mathrm{~mm}$ for males and $20 \mathrm{~mm}$ for females (Cornell modified). V4-V6 strain pattern on ECG was defined as ST-T segment vector shifted in direction opposite to mean QRS vector in V4-V6 leads.

Echocardiograms were performed according to standardized procedures described elsewhere [7-11]. Studies were recorded on videotape and digitized offline on a commercially available workstation. They were interpreted by a single experienced reader (GA) blinded to the study [7]. Left Ventricular Mass Index was calculated as follows: m-mode 2D driven from left ventricle, immediately under the edge of the mitralic flaps, at the start of ECG R wave, measure of interventricular septum thickness (IVS), diastolic diameter (DD) and posterior wall thickness (PW). Then the Devereux was applied as follows: Mass $=0.80 \times 1.04 \times\left[(\mathrm{DD}+\mathrm{PW}+\mathrm{IVS})^{3}-\mathrm{DD}^{3}\right]+0.6$ [12]. Left ventricular hypertrophy at echocardiogram was defined for values $>125$ $\mathrm{g} / \mathrm{m}^{2}$ for males and $>110 \mathrm{~g} / \mathrm{m}^{2}$ for females. Concentric remodeling was defined as a wall thickness-to-chamber radius ratio $>0.42$ in presence of a normal mass [13]. Diastolic dysfunction was described as E wave/A wave $<1$ or IVRT $>100$ [14].

Regarding epi-aortic vessel echo-color-Doppler, all patients were subjected to the investigation using a last generation power colordoppler with $7.5 \mathrm{mgHz}$ probes. Characteristics of the intima, pulsation index, resistance index, minimal speed, peak speed and mean speed were evaluated; an intima-media thickness (IMT) of $>1 \mathrm{~mm}$ was considered to be pathological [15]. Atherosclerotic plaques, if present, were described. A carotid was classified as being affected by plaque if there was a localized thickening $>1.2 \mathrm{~mm}$ that did not uniformly involve the whole left or right common carotid bifurcation with or without flow disturbance $[16,17]$. Ultrasonography was performed by physicians specifically trained on carotid vessels with at least a 10 -year experience in the ultrasound color-doppler technique and at least 1000 documented epiaortic examinations. They were blinded to the patient's antiretroviral therapy. Patients were submitted to the investigation in a supine position after at least $10 \mathrm{~min}$ of acclimatization in a comfortable room. Patients were informed that the investigation was non-invasive. The common, internal, and external carotid vessels were examined in the short and long axis. The percentage of stenosis was always quantified by calculating the stenosis areas in the short axis using a strong magnification. This was intended to distinguishing correctly the real lumen from plaques markedly hypoechoic with the color- or the power-doppler. The speed measurements were performed at an $45-60^{\circ}$ inclination with respect to the lumen. The morphological investigation of the plaque was performed using both ultrasonography and the ultrasound power color-doppler in order to better characterize the profile of the plaque and the IMT [17-21].

The ECG and echocardiographic data were compared to a control group of 40 hypertensive HIV-negative subjects with normal renal function, consecutively accessed during the same period at the outpatient facility of the Department of Cardiology and matched for median age, gender and blood pressure. The control group was composed of $1 / 3$ of the patients attending the out-patient clinic who were hypertensive but HIV negative, a samples size according with a right statistical analysis. Both patients with a previous hypertensive diagnosis but not in treatment (17 pts: $42.5 \%$ ) and patients of new diagnosis (23 pts: $57.5 \%$ ) were included in control group. Renal damage was evaluated by means of the microalbuminuria/creatininuria ratio on a spot urine sample, plus 24-hour albuminuria and proteinuria measurements (values respectively $>30 \mathrm{mg} / \mathrm{g}$ and $>3 \mathrm{~g} / 24 \mathrm{~h}$ were considered pathological) and by means of GRF assessment calculated both with Cockroft-Gault and CKD-EPI. Values of $<60 \mathrm{ml} / \mathrm{min}$ for one or both formulas were considered pathological. We did not use MDRD formula because it tends to overestimate if GFR $<60 \mathrm{ml} / \mathrm{min}$.

\section{Statistical analysis}

Data were expressed as mean +/- SD or median. Statistical comparison between mean values of each parameter was performed by the Mann-Withney U-test for non paired samples. Variation of each parameter of each groups of patients was performed by the nonparametric multiple pared sample test, according to the Friedman's test, which restitutes a Chi-square value.

\section{Results}

Of the 265 subjects examined, 61 (23.0\%) were hypertensive: 24 (39.3\%) had a previous hypertensive diagnosis but had never been treated for this condition, and 37 (60.7\%) had a new diagnosis; all had Grade 1 hypertension $(<160 / 100 \mathrm{mmHg}$ ). Mean age was 46.7 (range: $37-$ 59 ) and 42 were males. In $100 \%$ of cases, 24 -hour ABPM confirmed the hypertension diagnosed at screening and 17 (27.8\%) patients resulted non-dippers. Regarding antiretroviral therapy, 19 patients $(31.1 \%)$ were treated with a abacavir-based backbone, 39 (63.9\%) with a tenofovirbased backbone, and 3 (4\%) with a zidovudine-based backbone, while $31(50.8 \%)$ had a protease inhibitor as a third drug, and $29(47.5 \%)$ a non-nucleoside reverse transcriptase inhibitor. One patient (1.6\%) was not subjected to antiretroviral treatment.

The ECG showed pathological patterns in $64.3 \%$ of cases compared to $35.7 \%$ in the control group. The documented alterations were: left ventricle overload, V4-V6 strain, and signs of left ventricular hypertrophy.

Echocardiography demonstrated pathological results in 52 patients (85.2\%). 38 of them were dippers, 14 non-dippers. In patients with echocardiographic alterations, left ventricle parietal thickness was increased with concentric remodeling and hypertrophy. Diastolic filling and isovolumetric relaxation time were often modified. A similar pattern was present both in non-dipper and in dipper patients. When compared to the control group, HIV-positive patients showed a statistically significant tendency to concentric remodeling and concentric hypertrophy, even in presence of mild hypertension. Data 
regarding 24-hr ABPM, ECG and echocardiographic evaluations are summarized in Table 1.

Echocolor-Doppler examination detected intima-media thickness (IMT) of $>1 \mathrm{~mm}$ and/or atherosclerotic plaques in $72.1 \%$ of patients.

Evaluation of GFR with Cockroft-Gault and CKD-EPI, microalbuminuria/creatininuria ratio on spot urine sample, 24-hour albuminuria and proteinuria measurements demonstrated normal values in all subjects except one who was affected with a polycystic kidney disease.

\section{Discussion}

High blood pressure was found in $23 \%$ of our patients. Interestingly, in $60.7 \%$ of patients hypertension was diagnosed for the first time. This suggests that the proportion of undiagnosed hypertension among HIV patients is still relevant. The majority of these hypertensive patients are relatively young (mean age 46.7). The 24-hr ABPM confirmed the hypertension diagnosed at screening in $100 \%$ of the cases and indicates the importance of this diagnostic tool in confirming a suspect of hypertension. The 24-hr ABPM demonstrates a higher sensitivity for detection of the individual pressure load in addition to a better reproducibility and better predictor of clinical outcome with respect to the standard outpatient measures [12,22,23]. Moreover, 24-hr ABPM provides indications regarding the circadian pressure rhythm In fact, under physiological conditions, blood pressure is reduced about 10 $20 \%$ during sleep (dipping) [24]. Non-dipper patients are at a higher

\begin{tabular}{|c|c|c|c|}
\hline & HIV-1 patients & Control group & $\begin{array}{c}\text { p (significance } \\
\text { level 95\%) }\end{array}$ \\
\hline \multicolumn{4}{|l|}{ 24-hours Ambulatory Blood Pressure (BP) Monitoring } \\
\hline Mean day systolic BP (mmHg) & 148.15 & 149.04 & 0.8574 \\
\hline Mean day diastolic BP (mmHg) & 90.91 & 89.22 & 0.9026 \\
\hline Mean day frequency beats per minute (bpm) & 79.57 & 78.44 & 0.6254 \\
\hline Mean night systolic $\mathrm{BP}(\mathrm{mmHg})$ & 129.54 & 128.88 & 0.9123 \\
\hline Mean night diastolic $(\mathrm{mmHg})$ & 78.70 & 79.82 & 0.7895 \\
\hline Mean night frequency (bpm) & 70.58 & 71.72 & 0.7734 \\
\hline \multicolumn{4}{|l|}{ Dipper* } \\
\hline yes & $71.42 \%$ & $78.58 \%$ & \\
\hline no & $28.58 \%$ & $21.42 \%$ & \\
\hline \multicolumn{4}{|l|}{$\mathrm{ECG}^{\wedge}$} \\
\hline S V3 & 11.29 & 10.93 & 0.8276 \\
\hline $\mathrm{R}$ aVL & 6.50 & 7.00 & 0.7063 \\
\hline QT & 0.39 & 0.40 & 0.2390 \\
\hline FC & 68.50 & 70.86 & 0.6044 \\
\hline \multicolumn{4}{|l|}{ left ventricular overload** } \\
\hline yes & $57.2 \%$ & $35.7 \%$ & \\
\hline no & $42.8 \%$ & $64.3 \%$ & \\
\hline \multicolumn{4}{|l|}{$\begin{array}{l}\text { Left ventricular } \\
\text { hyperthrophy*** }\end{array}$} \\
\hline \multirow[b]{3}{*}{ Left Ventricular Internal Dimension diastole (mm) } & $64.3 \%$ & $35.7 \%$ & \\
\hline & $35.7 \%$ & $64.3 \%$ & \\
\hline & 46.88 & 48.90 & 0.3127 \\
\hline Left Ventricular Internal Dimension systole (mm) & 27.15 & 30.23 & 0.0190 \\
\hline Interventricular septum (mm) & 11.58 & 10.44 & 0.0244 \\
\hline Posterior wall (mm) & 10.49 & 8.94 & 0.0082 \\
\hline Left ventricular Ejection fraction (\%) & 74.29 & 72.86 & 0.4816 \\
\hline E wave velocity & 58.84 & 73.94 & 0.0003 \\
\hline A wave velocity & 72.75 & 60.02 & 0.0040 \\
\hline Isovolumic relaxation time (msec) & 117 & 96 & 0.0057 \\
\hline Left atrium (mm) & 29.27 & 29.93 & 0.6589 \\
\hline Aortic root (mm) & 33.46 & 30.70 & 0.0678 \\
\hline Relative wall thickness & 0.50 & 0.40 & 0.0020 \\
\hline Left ventricular mass (LVM) (g) & 231.92 & 196.94 & 0.1767 \\
\hline LVM indexed to body surface area $(\mathrm{g} / \mathrm{m} 2)$ & 117.86 & 101.93 & 0.2016 \\
\hline
\end{tabular}

${ }^{*} \mathrm{p}$-value $=1$

** p-value $=0.4495$

${ }^{* * *} \mathrm{p}$-value $=0.2568$

$\wedge$ ECG parameters were expressed in $\mathrm{mV}(1 \mathrm{mV}=10 \mathrm{~mm})$

Table 1: Results of 24-hr ABPM, ECG and echocardiographic evaluations and comparison with the control group. 
risk of organ damage [25-28] and cardiovascular complications [29-31]. In our study, $27.8 \%$ of patients resulted non-dipper, thus confirming the results of a previous study indicating that $35 \%$ of non-dippers were found among antiretroviral naïve HIV-positive patients compared to 15 $\%$ in HIV-negative subjects [32].

ECG frequently demonstrated pathologic patterns with typical signs of high blood pressure in HIV-positive patients with respect to HIV negatives (64.3 vs $35.7 \%$ ); even if not statistically significant, studies on a greater sample size are warranted. The most relevant finding of our study was the presence of left ventricle overload and V4V6 strain (changes of ventricular repolarization in these derivatives: flat-negative T waves with under leveling descending ST), symptomatic of a left ventricular hypertrophy. A pathologic EGC is generally typical of a long standing hypertension: this is in contrast with the young mean age of the patients.

Regarding the echocardiographic examination, the comparison of HIV patients with the control group indicates a statistically significant concentric remodeling and hypertrophy, apparently not justified by the degree of hypertension. Also among the patients with dipper behavior (generally considered a mild form of hypertension), we observed a significant tendency to echoic changes ( 38 out of 44 patients $=86.3 \%$ ).

At present, few studies have reported the prevalence of important abnormalities in cardiac structure and function among HAART subjects [33,34]. Hakim et al. in the Proceedings of the International AIDS Conference of 1996, presented an abstract regarding of echocardiographic findings in hospitalized HIV patients demonstrating that $50 \%$ of the patients had echocardiographic abnormalities [35]. A more recent study shows that ecocardiographic abnormalities are frequent among HIV patients, ranging from $18 \%$ to $40 \%$ [36]. These percentages are, however, lower with respect to those emerged in our study.

Moreover, a significant percentage of hypertensive patients (72.1\%) showed an intima-media damage at echocolor-Doppler evaluation. This percentage was markedly higher when compared to the $52.4 \%$ found in an our previous study on HIV patients treated with firstgeneration of PI-based regimens [37]. On the contrary, renal function seems spared in these subjects. This is not unexpected; in fact, the onset of renal damage due to hypertension generally requires a longer time with respect to vascular and cardiac damage.

In conclusion, our data highlights the importance of investigating arterial hypertension among our patients as it is a frequently undiagnosed condition, and illustrates the utility of 24-hr ABPM to confirm hypertension and to identify the non-dipper subject. Moreover, in our experience, the ECG, echocardiography and echocolor-Doppler examinations evidenced a premature tendency to organ damage in these patients; in particular, a statistically significant altered cardiac remodeling, when compared to those without HIV.

This stresses the need for an early diagnosis, including a complete instrumental evaluation to properly identify organ damage even at a subclinical level.

\section{Acknowledgements}

We thank Mrs Paulene Butts for the helpful review of the article.

\section{References}

1. Bergersen BM, Sandvik L, Dunlop O, Birkeland K, Bruun JN (2003) Prevalence of hypertension in HIV-positive patients on highly active antiretroviral therapy (HAART) compared with HAART-naive and HIV negative controls: results from a Norwegian study of 721 patients. Eur JClin Microbiol Infect Dis 22: 731-736.
2. Gazzaruso C Bruno R, Garzaniti A, Giordanetti S, Fratino P, et al. (2003) Hypertension among HIV patients: prevalence and relationships to insulin resistance and metabolic syndrome. J Hypertens 21: 1377-1382.

3. Jericó C, Knobel H, Montero M, Sorli ML, Guelar A, et al. (2005) Hypertension in HIV-infected patients: prevalence and related factors. Am J Hypertens 18 1396-1401.

4. European Society of Hypertension-European Society of Cardiology Guidelines Committee (2003) 2003 European Society of Hypertension-European Society of Cardiology guidelines for the management of arterial hypertension. J Hypertens 21: 1011-1053.

5. Takakuwa H, Ise T, Kato T, Izumiya Y, Shimizu K, et al. (2001) Diurnal variation of hemodynamic indices in non-dipper hypertensive patients. Hypertens Res 24: 195-201.

6. Birkenhäger AM, van den Meiracker AH (2007) Causes and consequences of a non-dipping blood pressure profile. Neth J Med 65: 127-131.

7. Vellozzi C, Brooks JT, Bush TJ, Conley LJ, Henry K, et al. (2009) The study to understand the natural history of HIV and AIDS in the era of effective therapy (SUN Study). Am J Epidemiol 169: 642-652.

8. Gottdiener JS, Bednarz J, Devereux R, Gardin J, Klein A, et al. (2004) American Society of Echocardiography: recommendations for use of echocardiography in clinical trials. A report from the American Society of Echocardiography's nomenclature and standards committee and the task force on echocardiography in clinical trials. J Am Soc Echocardiogr; 17: 1086-1119.

9. Lang RM, Bierig M, Devereux RB, Flachskampf FA, Foster E, et al. (2005) Recommendations for chamber quantification: a report from the American Society of Echocardiography's Guidelines and Standards Committee and the Chamber Quantification Writing Group, developed in conjunction with the European Association of Echocardiography, a branch of the European Society of Cardiology. J Am Soc Echocardiogr 18: 1440-1463.

10. Brucks S, Little WC, Chao T, Kitzman DW, Wesley-Farrington D, et al. (2005) Contribution of left ventricular diastolic dysfunction to heart failure regardless of ejection fraction. Am J Cardiol 95: 603-606.

11. Munagala VK, Jacobsen SJ, Mahoney DW, Rodeheffer RJ, Bailey KR, et al (2003) Association of newer diastolic function parameters with age in healthy subjects: a population-based study. J Am Soc Echocardiogr 16: 1049-1056.

12. Devereux RB, Roman MJ (1995) Evaluation of cardiac and vascular structure and function by echocardiography and other noninvasive techniques. In Laragh JH, Brenner BM (Eds.), Hypertension: patophysiology, diagnosis and management. Raven Press, New York, NY, 1969-1985.

13. Muiesan ML, Salvetti M, Monteduro C, Bonzi B, Paini A, et al. (2004) Left ventricular concentric geometry during treatment adversely affects cardiovascular prognosis in hypertensive patients. Hypertension 43: 731-738.

14. [No authors listed] (1998) How to diagnose diastolic heart failure. European Study Group on Diastolic Heart Failure. Eur Heart J 19: 990-1003.

15. Chambless LE, Heiss G, Folsom AR, Rosamond W, Szklo M, et al. (1997) Association of coronary heart disease incidence with carotid arterial wall thickness and major risk factors: the Atherosclerosis Risk in Communities (ARIC) Study, 1987-1993. Am J Epidemiol 146: 483-494.

16. Belcaro G, Nicolaides AN, Laurora G, Cesarone MR, De Sanctis M, et al. (1996) Ultrasound morphology classification of the arterial wall and cardiovascula events in a 6-year follow-up study. Arterioscler Thromb Vasc Biol 16: 851-856.

17. Nicolaides AN, Shifrin EG, Bradbury A, Dhanjil S, Griffin M, et al. (1996) Angiographic and duplex grading of internal carotid stenosis: can we overcome the confusion? J Endovasc Surg 3: 158-165

18. Steinke W, Meairs S, Ries S, Hennerici M (1996) Sonographic assessment of carotid artery stenosis. Comparison of power Doppler imaging and color Doppler flow imaging. Stroke 27: 91-94.

19. Mitchell DG (1990) Color Doppler imaging: principles, limitations, and artifacts Radiology 177: 1-10.

20. De Brai JM, Glatt B (1995) Quantification of atheromatous stenosis in the extracranial internal carotid artery. Cerebrovasc Dis 5: 414-426.

21. Ricotta JJ, Bryan FA, Bond MG, Kurtz A, O'Leary DH, et al. (1987) Multicente validation study of real-time (B-mode) ultrasound, arteriography, and pathologic examination. J Vasc Surg 6: 512-520. 
Citation: Maggi P, De Socio GVL, Volpe A, Lenoci F, Altizio S, et al. (2013) Organ Damage in HIV-Positive Patients with High Blood Pressure. J AIDS Clin Res 4: 248. doi: 10.4172/2155-6113.1000248

22. O'Brien E, Asmar R, Beilin L, Imai Y, Mancia G, et al. (2005) Practice guidelines of the European Society of Hypertension for clinic, ambulatory and self blood pressure measurement. J Hypertens 23: 697-701.

23. Hansen TW, Kikuya M, Thijs L, Björklund-Bodegård K, Kuznetsova T, et al. (2007) Prognostic superiority of daytime ambulatory over conventional blood pressure in four populations: a meta-analysis of 7,030 individuals. J Hypertens 25: $1554-1564$

24. Richardson DW, Honour AJ, Goodman AC (1968) Changes in arterial pressure during sleep in man. Hypertension 16: 62-78.

25. Verdecchia P, Schillaci G, Guerrieri M, Gatteschi C, Benemio G, et al. (1990) Circadian blood pressure changes and left ventricular hypertrophy in essential hypertension. Circulation 81: 528-536.

26. Schillaci G, Verdecchia P, Borgioni C, Ciucci A, Zampi I, et al. (1996) Association between persistent pressure overload and ventricular arrhythmias in essential hypertension. Hypertension 28: 284-289.

27. Marinakis AG, Vyssoulis GP, Michaelides AP, Karpanou EA, Cokkinos DV, et al. (2003) Impact of abnormal nocturnal blood pressure fall on vascular function. Am J Hypertens 16: 209-213.

28. Shimada K, Kawamoto A, Matsubayashi K, Nishinaga M, Kimura S, et al (1992) Diurnal blood pressure variations and silent cerebrovascular damage in elderly patients with hypertension. J Hypertens 10 : 875-878.

29. Verdecchia P, Porcellati C, Schillaci G, Borgioni C, Ciucci A, et al. (1994) Ambulatory blood pressure. An independent predictor of prognosis in essential hypertension. Hypertension 24: 793-801.

30. Fagard RH, Celis H, Thijs L, Staessen JA, Clement DL, et al. (2008) Daytime and nighttime blood pressure as predictors of death and cause-specific cardiovascular events in hypertension. Hypertension 51: 55-61.

31. Boggia J, Li Y, Thijs L, Hansen TW, Kikuya M, et al. (2007) Internationa Database on Ambulatory blood pressure monitoring in relation to Cardiovascular Outcomes (IDACO) investigators. Prognostic accuracy of day versus night ambulatory blood pressure: a cohort study. Lancet 370: 1219-1229.

32. De Socio GV, Bonfanti P, Martinelli C, Ricci E, Pucci G, et al. (2010) Negative influence of HIV infection on day-night blood pressure variability. J Acquir Immune Defic Syndr 55: 356-360.

33. Meng Q, Lima JA, Lai H, Vlahov D, Celentano DD, et al. (2002) Use of HIV protease inhibitors is associated with left ventricular morphologic changes and diastolic dysfunction. J Acquir Immune Defic Syndr 30: 306-310.

34. Hsue PY, Farah HH, Bolger AF, Palav S, Ahmed S, et al. (2008) Diastolic dysfunction is common in asymptomatic HIV patients [abstract 979]. In: Program and abstracts of the 15th conference on retroviruses and opportunistic infections. Massachusetts, Boston.

35. Hakim JG, Matenga JA, Siziya S (1996) Myocardial dysfunction in human immunodeficiency virus infection: an echocardiographic study of 157 patients in hospital in Zimbabwe. Heart 76: 161-165.

36. Mondy KE, Gottdiener J, Overton ET, Henry K, Bush T, et al. (2011) High Prevalence of Echocardiographic Abnormalities among HIV-infected Persons in the Era of Highly Active Antiretroviral Therapy. Clin Infect Dis 52: 378-386.

37. Maggi P, Lillo A, Perilli F, Maserati R, Chirianni A; PREVALEAT Group (2004) Colour-Doppler ultrasonography of carotid vessels in patients treated with antiretroviral therapy: a comparative study. AIDS 18: 1023-1028. 